\title{
Remote sensing the vertical profile of cloud droplet effective radius, thermodynamic phase, and temperature
}

\author{
J. V. Martins ${ }^{1,2}$, A. Marshak ${ }^{2}$, L. A. Remer $^{2}$, D. Rosenfeld ${ }^{3}$, Y. J. Kaufman ${ }^{2}$, R. Fernandez-Borda ${ }^{2,4}$, I. Koren ${ }^{5}$, \\ A. L. Correia ${ }^{7}$, V. Zubko $^{6}$, and P. Artaxo ${ }^{7}$ \\ ${ }^{1}$ Department of Physics, and Joint Center for Earth Systems Technology, University of Maryland Baltimore County, \\ Baltimore, MD, USA \\ ${ }^{2}$ Laboratory for Atmospheres, NASA - Goddard Space Flight Center, Greenbelt, MD, USA \\ ${ }^{3}$ Institute of Earth Sciences, The Hebrew University of Jerusalem, Israel \\ ${ }^{4}$ Joint Center for Earth Systems Technology, University of Maryland Baltimore County, Baltimore, MD, USA \\ ${ }^{5}$ Department of Environmental Sciences, Weizmann Institute, Rehovot, Israel \\ ${ }^{6}$ United States Naval Observatory, Washington, DC, USA \\ ${ }^{7}$ Institute of Physics, University of Sao Paulo, Brazil
}

Received: 7 November 2006 - Published in Atmos. Chem. Phys. Discuss.: 30 March 2007

Revised: 20 July 2011 - Accepted: 5 August 2011 - Published: 16 September 2011

\begin{abstract}
Cloud-aerosol interaction is a key issue in the climate system, affecting the water cycle, the weather, and the total energy balance including the spatial and temporal distribution of latent heat release. Information on the vertical distribution of cloud droplet microphysics and thermodynamic phase as a function of temperature or height, can be correlated with details of the aerosol field to provide insight on how these particles are affecting cloud properties and their consequences to cloud lifetime, precipitation, water cycle, and general energy balance. Unfortunately, today's experimental methods still lack the observational tools that can characterize the true evolution of the cloud microphysical, spatial and temporal structure in the cloud droplet scale, and then link these characteristics to environmental factors and properties of the cloud condensation nuclei.

Here we propose and demonstrate a new experimental approach (the cloud scanner instrument) that provides the microphysical information missed in current experiments and remote sensing options. Cloud scanner measurements can be performed from aircraft, ground, or satellite by scanning the side of the clouds from the base to the top, providing us with the unique opportunity of obtaining snapshots of the cloud droplet microphysical and thermodynamic states as a function of height and brightness temperature in clouds at several development stages. The brightness temperature profile
\end{abstract}

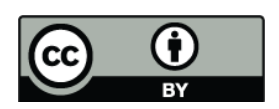

Correspondence to: J. V. Martins (martins@umbc.edu) of the cloud side can be directly associated with the thermodynamic phase of the droplets to provide information on the glaciation temperature as a function of different ambient conditions, aerosol concentration, and type. An aircraft prototype of the cloud scanner was built and flew in a field campaign in Brazil.

The CLAIM-3D (3-Dimensional Cloud Aerosol Interaction Mission) satellite concept proposed here combines several techniques to simultaneously measure the vertical profile of cloud microphysics, thermodynamic phase, brightness temperature, and aerosol amount and type in the neighborhood of the clouds. The wide wavelength range, and the use of multi-angle polarization measurements proposed for this mission allow us to estimate the availability and characteristics of aerosol particles acting as cloud condensation nuclei, and their effects on the cloud microphysical structure. These results can provide unprecedented details on the response of cloud droplet microphysics to natural and anthropogenic aerosols in the size scale where the interaction really happens.

\section{Introduction}

Clouds and precipitation play a crucial role in the Earth's energy balance and water cycle (Andreae et al., 2008; Forster et al., 2007). In addition, clouds and the release of latent heat during precipitation provide much of the energy that drives

Published by Copernicus Publications on behalf of the European Geosciences Union. 
the circulation, especially the tropical circulation. Thus, to understand atmospheric dynamics we need to understand cloud development and the factors that influence precipitation in cloud systems. Clouds are highly dynamic systems, strongly controlled by thermodynamic parameters and by the presence, concentration and characteristics of cloud condensation nuclei $(\mathrm{CCN})$. Cloud condensation nuclei $(\mathrm{CCN})$ are a subset of the aerosol particle population, and are required to form cloud droplets (McFiggans et al., 2006). To understand clouds and precipitation at the microphysical level we must understand cloud-aerosol interaction at this level. A landmark in our understanding of aerosol-cloud interaction was the theory proposed by Twomey (1977) in which he explained that high concentrations of aerosols can reduce the effective droplet size and increase cloud albedo for a constant amount of liquid water. Albrecht (1989) expanded this theory by explaining that high aerosol concentrations can also narrow the droplet size distribution, suppressing precipitation and prolonging cloud lifetime of marine stratocumulus. Rosenfeld et al. (2006a) showed that the feedback through precipitation greatly enhances the sensitivity of the cloud cover and dynamic regime to small differences in aerosol concentrations. Cloud-aerosol interactions dominate not only the dynamics of marine shallow clouds, but also the lifetime and the vertical disposition of latent heat of deep convective clouds over ocean and even more strongly over land. Observational data (Williams et al., 2002; Andreae et al., 2004; Rosenfeld, 2006a; Rosenfeld et al., 2009; Koren et al., 2010b, Prenni et al., 2009) and simulation studies Khain and Lynn (2009) suggest that aerosol-induced changes of cloud microstructure have profound impact on the precipitation, dynamic evolution and vertical disposition of latent heat release.

Aerosols affect clouds also by their radiative properties. Hansen et al. (1997) suggested that absorbing aerosols can effectively decrease cloud lifetime by heating the cloud layers and promoting evaporation of cloud droplets. Ackerman et al. (2000) modeled this situation and Koren et al. (2004) observed quantitatively the inhibition of certain types of clouds in the Amazon due to the presence of heavy smoke. Kaufman and Koren (2006) analyzing AERONET data (Holben et al., 1998) found that absorbing and non-absorbing aerosols affect cloud cover differently: while absorbing aerosols prevent clouds from forming, nonabsorbing aerosols enhance cloud cover by suppressing precipitation. The trade-off between microphysical and radiative aerosol effects is presented as a simple analytical model and demonstrated using satellite observations (Koren et al., 2008; Rosenfeld et al., 2008a).

All of these cloud-aerosol interaction theories and studies have one thing in common. They are all focused on how cloud-aerosol interaction affect the earth's radiation budget. One of the reasons for this focus is the emphasis given by the climate community, who cites the IPCC (Intergovernmental Panel on Climate Change) reported uncertainty in radiative forcing estimates due to the uncertainty introduced by cloud-aerosol interactions. In parallel, new dimensions to cloud-aerosol interaction (summarized in Rosenfeld, 2006a) have been introduced by the satellite methodology of Rosenfeld and Lensky (1998) and applied subsequently in Rosenfeld (1999, 2000), Ramanathan et al. (2001); Rudich et al. (2002); Rosenfeld et al. (2001, 2002, 2007, 2008b) Rosenfeld and Woodley (2003); Rosenfeld and Ulbrich (2003). These satellite inferences were supported by aircraft measurements of the aerosol effect on the cloud microphysics and precipitation (Andreae et al., 2004; Rosenfeld et al., 2006b, 2008c). Also, another component of the energy budget driven by latent heating release was recently proposed by Rosenfeld et al. (2008a). This new focus claims that cloudaerosol interaction is no longer simply a radiative problem, but one affecting the water cycle, the weather, and the total energy balance including the spatial and temporal distribution of latent heat release. In particular, Andreae et al. (2004 - see Fig. 1) used in situ measurements to show how the vertical profile of effective radius changed as a funciton of the amount of biomass burning aerosols.

Although several basic processes explaining cloud formation and evolution are well established, there are many unresolved fundamental issues concerning the understanding of real clouds and their temporal and spatial evolution. The explanation of some of these issues, like the lack of fundamental understanding of the glaciation of clouds, or the extent by which warm rain dominates clouds that extend to very cold temperatures near the tropopause under different aerosol conditions have been targeted by the scientific community for a long time (e.g. McGraw and Liu, 2003). To alleviate some of this uncertainty several field campaigns have been performed to study developing convective systems (CRYSTAL-FACE, CAMEX, SMOCC, TC4 and others). However, these experiments lacked the experimental observations that could characterize the true evolution of the cloud microphysics spatial and temporal structure, and then link these development characteristics to environmental factors and available $\mathrm{CCN}$.

Traditionally, our understanding of the changing vertical structure of a developing cloud was mostly based on radar and in situ measurements collected by aircraft. Precipitation radars tell us about the vertical development of precipitation sized droplets in clouds and give information on the thermodynamic phase of the hydrometeors. Millimeter wavelength cloud radars (Clothiaux et al., 1999) determine cloud boundaries (cloud bottoms and tops). Though they also provide vertical velocities of cloud constituents, they have very limited capability (e.g. Frisch et al., 1995) of measuring vertical profiles of small droplets. Radars alone cannot tell us a complete microphysical story because they miss the characterization of the smaller-sized cloud droplets where the story begins. In situ measurements can measure cloud droplets, but they are very limited in terms of characterizing the vertical structure of clouds. In many cases, the time an aircraft 


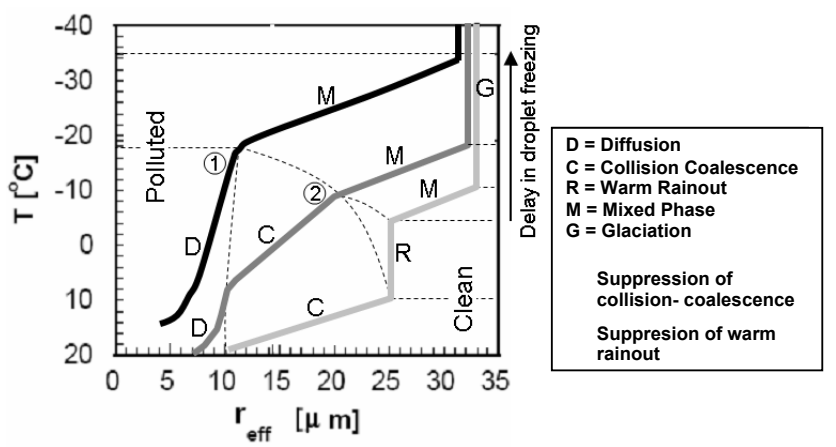

Fig. 1. Conceptual diagram adapted from Rosenfeld and Woodley (2003), describing 5 microphysical stages (droplet growth by diffusion, collision-coalescence, warm rainout, ice-water mixed phase, and glaciated phase) common to deep convective clouds and their response to the concentration of pollution aerosols. The bottom curve shows the case of a maritime environment with low $\mathrm{CCN}$ concentration and the possibility of warm rain processes; the middle curve corresponds to commonly found continental cases, where the larger number of $\mathrm{CCN}$ aerosols helps to suppress warm rain process and glaciation starts at slightly lower temperatures; the top curve represents extremely polluted cases where the very large number of CCNs produce smaller and more numerous droplets at cloud base suppressing the beginning of collision-coalescence processes, and postponing the start of droplet freezing to much lower temperatures. Intermediate situations to the above curves are also possible.

would take to climb from cloud base to cloud top measuring its physical properties is enough for the cloud to form, evolve and dissipate. In many cases there is also the danger of flying inside highly convective systems and there are often altitude limitations for most of the available research aircraft.

Passive satellite remote sensing measurements have provided information that has led to the revolutionary rethinking of our perceptions of cloud-aerosol interaction (Rosenfeld and Lensky, 1998). Satellites can provide insight and an impressive statistical data-base of cloud microphysics at cloud top, coupled to column aerosol properties surrounding the cloud. However, all these satellite inferences have been based on 1 to $2 \mathrm{~km}$ resolution single snap shot imagery of the cloud tops, or large statistics on $1 \times 1^{\circ}$ resolution MODIS data (Kaufman et al., 2005; Koren et al., 2005). The satellite-derived vertical evolution is a result of composition of many cloud pixels at different degrees of evolution, assuming that the ensemble represents the evolution of a single cloud with height and time (Freud et al., 2008). Additional support for this assumption was obtained from rapid scan of geostationary microphysical images tracking the evolution of individual clouds (Lensky and Rosenfeld, 2006), but with the poor spatial resolution that can be obtained from a geostationary orbit. While this method of inferring vertical evolution is useful, it relies on strong assumptions and poses many limitations.

More recently, with the launch of CloudSat with its $94 \mathrm{GHz}$ nadir-looking radar, we have for the first time global sampling of the vertical profiles within clouds (Stephens et al., 2002, 2008). Standard products for CloudSat include profiles of reflectivity that are used to retrieve macrophysical cloud properties, such as profiles of cloud optical thickness, for example. However, the $94 \mathrm{GHz}$ radar (equivalent wavelength on the order of $1 \mathrm{~mm}$ ) is not sensitive to scattering from cloud particle sizes smaller than $10 \mu \mathrm{m}$ in radius for water droplets or $50 \mu \mathrm{m}$ in radius for ice crystals, a full 1 or 2 orders of magnitude smaller than the radar's wavelength. CloudSat does not provide vertical profiles of cloud particle effective radius as a standard product. The CloudSat effective radius product is a total column parameter (Stephens et al., 2008). Combining CloudSat with observations and products from other A-Train sensors may compensate for the radar's insensitivity, but even multi-sensor studies develop proxies for vertical profiles of cloud microphysics rather than directly retrieving the quantitative profiles of particle effective radius (Suzuki et al., 2010).

Despite of all the information gained from in situ measurements in the clouds and from the large remote sensing statistics, there is still a big gap to be filled. We must add large statistics with detailed information about the cloud vertically-resolved particle effective radius on a cloud by cloud basis. We are after a deep understanding of the processes driving the effect of aerosol on clouds. We need a methodology that will either prove or refute the Rosenfeld and Lensky (1998) hypothesis by providing simultaneously:

- a snapshot with similar or better level of detail of the vertical structure of cloud microphysics than in situ measurements can provide,

- large enough statistics that would allow us to make confident conclusions about the physical processes inside the cloud.

These two conditions cannot be met today by either remote sensing or in situ capabilities. Each in situ cloud measurement, takes at least tens of minutes of the cloud lifetime which allow many changes in the cloud structure. The collection of data showed by Andreae et al. (2004) and in Fig. 8 of Rosenfeld et al. (2006b) took more than one experiment, in different countries, and different years to collect enough data for their conclusions. Also, in situ aircraft cannot penetrate the strongest thunderstorms.

Here, we demonstrate a new approach that provides the information missed in experiments and in today's remote sensing options: the details of vertical, horizontal and temporal development of cloud microphysical structure in a developing cloud. We will use new measurements of cloud microphysics in conjunction with other measurements of cloud and aerosol characteristics to improve our understanding of the factors influencing cloud development, and the onset and character of precipitation. The methodology presented here can also validate the cloud top ensemble approach described by Freud et al. (2008). 
In order to perform these measurements a new aircraft instrument (the cloud scanner system) was developed and built to observe cloud side radiances from the ultraviolet to the thermal infrared. The results obtained with this system can be combined with additional aerosol measurements to provide a full scenario for studying aerosol-cloud interactions. The current model of the cloud scanner consists of a scanning spectrometer system with a $1^{\circ}$ instantaneous field of view, $120^{\circ}$ total scanning capability, $1 \mathrm{~nm}$ spectral resolution from $350-2500 \mathrm{~nm}$, and one thermal infrared band centered at $11 \mu \mathrm{m}$. The first results from the cloud scanner measurements in tropical clouds over Brazil will be presented in Sect. 3 of this paper.

\subsection{Effect of aerosol on cloud microphysics, thermodynamics, and precipitation}

Figure 1 illustrates the changes we might observe in a cloud as more and more $\mathrm{CCN}$ become available. The figure is based on the conceptual models of Rosenfeld and Lensky (1998) and Rosenfeld and Woodley (2003), which were later confirmed by the modeling work of Khain et al. (2001) and by the observations presented in Fig. 5 of Andreae et al. (2004). The plot shows the effective radius of cloud particles, both water droplets and ice particles, as a function of temperature in a cloud. The temperature is plotted on the vertical axis because it is strongly dependent on altitude and thus used as a proxy for height in the cloud.

The cleanest cloud, the one with the least number of $\mathrm{CCN}$ is represented by the lightest gray profile. Traveling upwards from the base of this clean cloud provides immediately a regime of collision-coalescence where liquid droplets quickly grow to larger sizes with the cloud updraft. Here there is the largest increase of $r_{\text {eff }}$ with height (Region $\mathrm{C}$ in Fig. 1). At relatively low altitude the cloud droplets are large enough to begin falling as warm rain (Region $\mathrm{R}$ in Fig. 1), and the droplet growth slows. If the updraft continues, the water droplets begin to freeze at a relatively low altitude, entering a second growth region where ice is forming in a mixed phase regime (Region $\mathrm{M}$ in Fig. 1). Soon all the particles are ice and the glaciated region begins (Region $G$ in Fig. 1).

By contrast, the heavily polluted case with an overabundance of $\mathrm{CCN}$ is denoted by the black curve. Here, at cloud base, the cloud water has been divided into many more but smaller cloud droplets than in the gray curves (Twomey, 1977). The cloud droplets start at smaller sizes and they remain smaller as we follow the updraft to colder temperatures. The smaller droplets are too small to collide and coalesce and they grow by diffusion processes only (Region D in Fig. 1). Diffusional growth is much slower. The droplets never reach liquid precipitation sizes and begin to freeze only at much colder temperatures, reaching the mixed phase region and glaciation levels much higher in the cloud. At the extreme, liquid cloud drops can reach the homoge- neous freezing isotherm of $-38^{\circ} \mathrm{C}$, as observed by in situ measurements of continental convective clouds (Rosenfeld and Woodley, 2000; Rosenfeld et al., 2006b, 2008b). The medium gray profile shows a case with a moderate amount of $\mathrm{CCN}$.

The cloud responds to increases of available CCN by suppressing collision-coalescence due to the more numerous and relatively smaller droplets and narrower size distribution widths, and the delay on the water droplet freezing allowing in some case the supercooled water to exist closer to temperatures of homogeneous ice nucleation of small cloud droplets $\left(-38^{\circ} \mathrm{C}\right)$. Khain et al. (2001) pointed out that the probability of immersion freezing of small droplets with radii below $10 \mu \mathrm{m}$ is negligibly small, as well as the effect of contact freezing. Heterogeneous freezing is just not efficient in these cases. The collision efficiencies between ice crystals with size below $100 \mu \mathrm{m}$ and small droplets are close to zero. Cotton (2005) noticed that there are two theories describing the nucleation of a cloud droplet or raindrop by an ice nucleus, which is immersed within the drop (the immersion-freezing). One stochastic theory saying that at a given degree of supercooling not all droplets will freeze at the same time, and a second - called singular theory - holding that at a given degree of supercooling, the probability of freezing depends solely on the likelihood that the droplet contains an active freezing nuclei. Both theories predict that the probability of freezing increases exponentially with the degree of supercooling and with the volume (or size) of the droplet. Thus for small cloud droplets at small degrees of supercooling, this mechanism of nucleation is not effective, re-affirming the delay in droplet freezing following the smaller cloud droplets caused by high concentration of pollution aerosols that are not active as ice forming nuclei at temperatures much higher than $-38^{\circ} \mathrm{C}$.

This delay of the glaciation process is an additional feedback and strong aerosol-cloud interaction effect that further delays the droplet growth and the onset of precipitation. Suppressing rainout will bring additional supercooled water aloft, and so release more latent heat of freezing (Rosenfeld, 2006a; Rosenfeld et al., 2008a). Lohmann (2002) also discussed the effect of soot particles on glaciation, and on the lifetime of ice and mixed phase clouds. Although this paper was focused on the radiative cloud-mediated effect of soot aerosols, the same processes affect the cloud lifetime and precipitation. Her results indicate that soot particles, acting as ice nuclei, can significantly change the efficiency of droplet freezing and contribute to modulate the droplet growth and the onset of precipitation in convective clouds.

Therefore, there are two measurable cloud responses to increasing $\mathrm{CCN}$ in a cloud: (1) the change in cloud effective radius profiles and (2) the change in altitude of the glaciation level. Our proposed remote sensing method is able to resolve both of these responses. 


\section{Measurements of the cloud side radiances and their information content}

\subsection{Traditional passive remote sensing of cloud top properties}

Traditional remote sensing of cloud microphysical properties assumes that satellites observe only cloud tops, and that clouds behave like infinite plane parallel objects. The solar spectrum reflected by clouds and measured by satellites has been long used to measure cloud microphysical and thermodynamic properties. Nakajima and King (1990), and Nakajima et al. (1991) established a two parameter diagram (hereafter called in this paper by Nakajima-King diagram) that converts cloud reflected radiances in two wavelengths (one non-absorbing, usually 0.66 or $0.87 \mu \mathrm{m}$, and one absorbing, usually $1.6,2.1$, or $3.7 \mu \mathrm{m}$ ) into two physical parameters of the cloud: effective radius of the upper part of the cloud, and the total cloud optical depth. The cloud reflectance in the absorbing wavelength is mainly sensitive to the droplet or ice crystals effective radius while the cloud reflectance in the non-absorbing wavelength is more sensitive to the cloud optical depth. Platnick et al. (2003) reviewed several algorithms used for the retrieval of cloud top properties using MODIS observations, including effective radius, thermodynamic phase, and cloud top pressure.

As proposed by Rosenfeld and Lensky (1998), and further applied in large statistics of convective clouds by Koren et al. (2005), and on shallower clouds by Kaufman et al. (2005), the satellite remote sensing of cloud top properties in a large cloud field containing numerous clouds of different heights has provided important information on the aerosol effect on the vertical profile of the droplet effective radius. The main assumption in this approach is that a cloud top at a given altitude (and/or a given temperature) represents the same state as a point at the same altitude, inside a higher cloud (Freud et al., 2008). Another important assumption here is that the whole cloud field, which in some cases may represent hundreds of kilometers, is homogeneously subjected to the same meteorological and aerosol conditions with the assumed time - space exchangeability (Lensky and Rosenfeld, 2006).

Following these important results, the main motivation for the current work is to develop a methodology to provide the vertical profile of cloud droplet sizes, and thermodynamic phase without the above strong assumptions of the cloud top remote sensing approach, and with better statistics and temporal resolution than those provided by in situ measurements.

\subsection{What can we learn by observing the cloud sides?}

Equivalently to cloud tops, solar radiation photons reflected by the side of the clouds also carry information about the microphysical and thermodynamical properties of cloud droplets. Similarly to the cloud top case, the absorption properties of water and ice particles inside the clouds is propor- tional to their effective radius (Twomey and Bohren, 1980), and analogues to the Nakajima-King type of diagrams can also be constructed for this particular geometry. Furthermore, the cloud side radiances have the additional advantage of carrying information about the vertical position in the cloud profile, allowing for the vertical profiling of cloud droplet (particles) sizes and thermodynamic phase. As discussed earlier, this vertical profile is very sensitive to the aerosol conditions imposed to the cloud field. Therefore, cloud side measurements provide us with the unique opportunity of obtaining snapshots of the cloud particle microphysical and thermodynamic states as a function of height and brightness temperature. The brightness temperature profile of the cloud side can be directly associated with the thermodynamic phase of the particles to provide information on the glaciation temperature of the droplets as a function of different ambient conditions, aerosol concentration, and type. In general, measurements from the cloud side can provide essential information about the evolution of cloud microphysical processes and the important steps that droplets and ice particles undergo before the onset of precipitation.

The combination of these key elements can provide unprecedented information to help our understanding of the effect of aerosols on cloud microphysics and precipitation. These measurements can be done from aircraft, ground, or satellite by scanning the side of the clouds from the base to the top, measuring the radiance in selected wavelengths suitable for the retrieval of effective radius, temperature, and the thermodynamic phase. Cloud side measurements have been utilized before from the ground, for the separation between cloud droplet ice and water phases (Pilewskie and Twomey, $1987 \mathrm{a}, \mathrm{b}$ ), but, to our knowledge, this is the first time that this approach is being applied to retrieve the vertical profile of cloud droplet size, as a function of phase, and brightness temperature.

\subsection{Ground based and aircraft observation geometry of cloud sides}

Cloud side observations can be performed from the ground, from mountain tops, aircraft or from satellites with specific advantages and disadvantages on each case. The main disadvantage of the ground-based observations is the relatively thick atmospheric column observed between the instrument and the cloud mainly at water vapor absorption channels and, in particular, in thermal wavelengths where the combination between high temperatures near the surface and the high water vapor emissivity produce large background noise over the lower temperature for the cloud of interest. Another disadvantage of observations from the ground is the prevalence of cloud shadows due to a range of scattering angles that deviates from the direct backscattering direction when the sun is directly behind the observer. Observations from low altitude aircraft and mountain tops eliminate most of the problems with water vapor absorption, temperature and its IR 


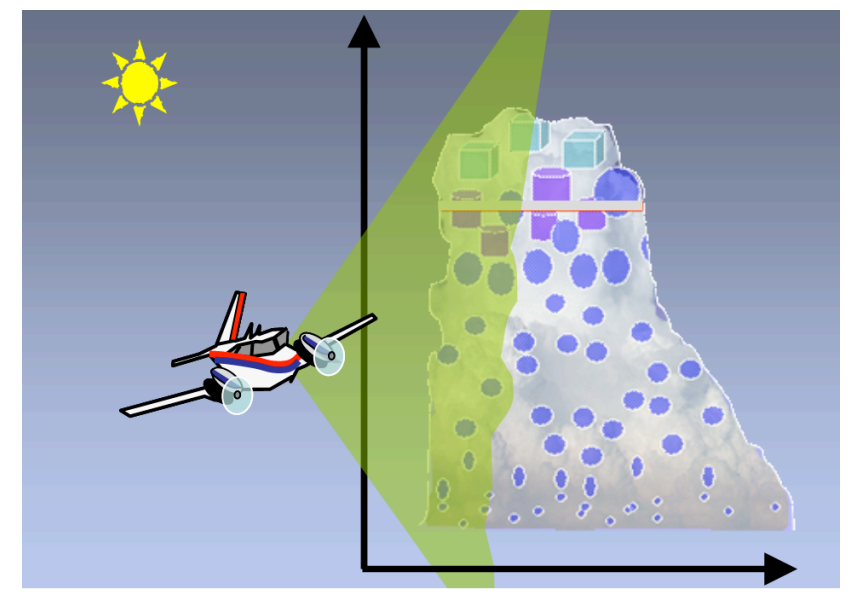

Fig. 2. Cloud side observations from low altitude aircraft.

emissivity. Figure 2 show a schematic diagram of low altitude aircraft observations of deep convective clouds using a side scanning geometry. In this case, the aircraft flies on the side of convective clouds and measures the cloud from the base to the top in several wavelengths. This is the geometry that was used in the measurements presented here, with the detail that clouds were observed from far distances so that the view angle range was relatively small. Although Rayleigh scattering, water vapor absorption, and IR emissivity issues are minimized in this case, cloud shadows in the upper views, and the interpretation of the multi-angle distribution in the analysis of a single cloud can still be troublesome. The best geometry for cloud side observations would actually be performed by high altitude aircraft or satellites, where the platform is completely above the cloud, and side radiances can be observed from the base to the top of the cloud with a single view angle orientation with the sun located directly behind the sensor. By definition, this geometry eliminates the possibility of shadows in the observed pixel, and the noise introduced by water vapor in the lower atmosphere, although not eliminated, is minimized. Multiangle satellite observations like the ones by MISR (Multi-angle Imaging SpectroRadiometer - (Diner et al., 1998) have provided some cloud side observations but, unfortunately, MISR lacks the right wavelengths to provide the vertical profile of cloud microphysics and thermodynamic phase explored here.

Figure 3 shows a more appropriate observing geometry using a high altitude aircraft. The main advantage in this case is that the view zenith angle is constant for all portions of the cloud. This geometry advantage allows for better interpretation of the thermal data producing meaningful $-d T / d x$ (where $x$ is the displacement of the aircraft) results clearly separating cloud tops from cloud sides, and providing estimates of the cloud side (relative) slanted slope. The cloud tops will present the lowest $-d T / d x$ values, while the cloud sides with oblique slopes will present lower $-d T / d x$ values

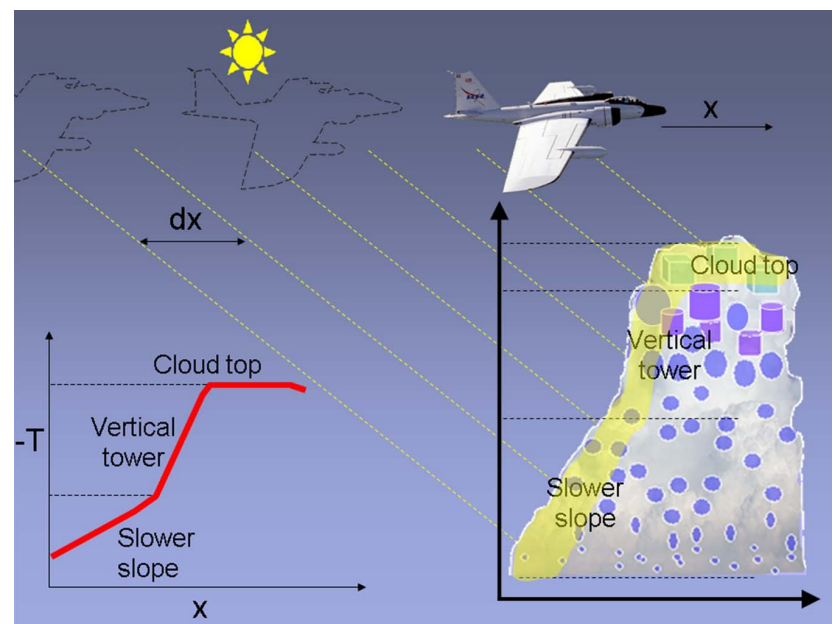

Fig. 3. Schematic representation of cloud side measurements performed from high altitude aircraft or satellite. In this geometry, the cloud is always observed from a single view angle perspective and different altitudes of the cloud are observed by moving the aircraft rather than employing a moving scan mirror. The geometry can always be optimized to reduce shadows and other issues. The insert in the lower left corner shows an idealized measure of temperature as a function of height of the cloud to the right. The more vertical the cloud wall, the more quickly the temperature changes with height. Cloud tops display almost constant temperature with the satellite displacement. The expression "slower slope" in the figure refers to regions where the cloud wall is not vertical, producing slower changes in temperature as a function of cloud height.

than the deep convective columns with nearly vertical slopes. This relative classification of the cloud side slopes is important for the selection of the 3-D look-up-table model to interpret the cloud side radiances. The relative angle between the solar incidence and the cloud side wall is an important factor for the inversion of the droplet effective radius profile, as it will be discussed in the next section. The conceptual plot on the left lower corner of Fig. 3 shows is an example of the thermal measurement results for the cloud on the right hand side. The negative slope $-d T / d x$ can be associated with the geometric slope $(d z / d x)$ in the real cloud, relating the thermal IR brightness temperature measurements with the cloud geometry. In nature cloud sides are not as smooth as those depicted in Fig. 3 or those clouds modeled in the radiative transfer simulations described below. Resolution of the sensor can be selected to be sufficiently fine to resolve the expected vertical structure of the conceptual cloud model of Fig. 1 and yet sufficiently coarse to measure the macroscale slope of $-d T / d x$. The slanted lines of Fig. 3 showing the observation resolution provide an example of such an optimization. 


\subsection{3-D radiative transfer in clouds}

It seems natural that an accurate treatment of the cloud side radiances requires the cloud to be treated as a threedimensional (3-D) object. There are several degrees of complexity that can be considered in the 3-D simulation of clouds. For accurate simulations one should account for the cloud vertical structure (variation on cloud droplet or ice crystal size and shape, mixing between ice and water, and variation in water path), shadowing effects, interactions between the cloud and the underlying surface, realistic distributions of clouds in a cloud field, and interaction between neighboring clouds. In this study we will use a series of simplifying hypotheses in order to define a simple but still realistic scheme for obtaining detailed microphysical information from the remote sensing of the cloud side spectral radiances. For simplicity, in our quantitative retrievals, we will focus on the illuminated side (directions near the backward scattering) of an isolated convective cloud lying over a dark surface, ignoring the exchange of photons between clouds. A more realistic simulation of stochastic cloud fields is performed in Marshak et al. (2006). In that paper, several cloud fields with the same stochastic properties as real clouds are generated assuming variable cloud tops and vertical profiles of water droplet, mixed phase, and ice particles. Here we compare the results from Marshak et al. (2006) simulations with our simplified approximations.

In order to build a look-up-table (LUT) for our quantitative retrievals from the cloud side, rigorous 3-D radiative transfer simulations were performed with the SHDOM (Spherical Harmonics Discrete Ordinate Method - Evans, 1998 and Evans and Marshak, 2005) code for cylindrical clouds consisting of homogeneous water droplets, or different types of ice crystal habits (Yang et al., 2000). Individual cylindrical clouds were simulated with effective radii varying between 5 and $40 \mu \mathrm{m}$, optical depths $\tau_{z}=50$ and 100 , and horizontal optical distances varying from $\tau_{x}=10$ to 100 , or optical distance aspect ratios $\tau_{z} / \tau_{x}=1,2,3,4$ and 5, over dark surface ( surface albedo $=0$ ). These simulations included Rayleigh scattering but neglected gaseous absorption. The main purpose of this initial simulation was to compare the extent of the cloud edge effects on the side radiances, and compare results with a traditional plane parallel approximation. For quality assurance, some results from this model were also intercompared with Monte Carlo simulations (Evans and Marshak, 2005) and showed good agreement. The SHDOM simulations were performed at 4 wavelengths $(0.67,2.1,2.25$, and $11 \mu \mathrm{m}$ ) with several solar and viewing geometries, in order to produce general LUTs for interpreting the cloud side measurements.

Figure 4 shows $2.1 \mu \mathrm{m}$ and $0.66 \mu \mathrm{m}$ reflectance from the side and top of the simplified cylindrical cloud illuminated with $60^{\circ}$ solar zenith angle and viewed at $45^{\circ}$ viewing zenith angle. Due to the larger absorption by water droplets at $2.1 \mu \mathrm{m}$, the side radiances at this wavelength quickly ap-

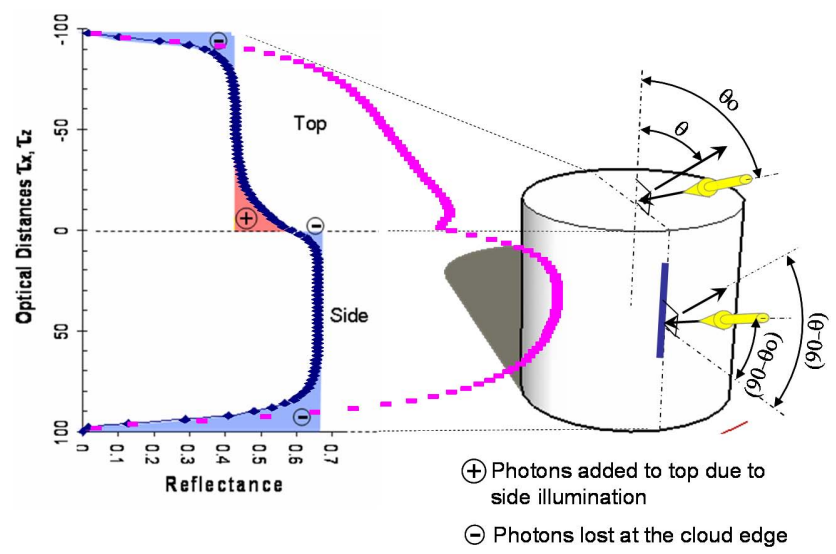

Fig. 4. Cloud side and top radiances at $2.1 \mu \mathrm{m}$ (blue) and $0.66 \mu \mathrm{m}$ (pink) calculated with the 3-D radiative transfer code SHDOM for a simplified cylindrical cloud with homogeneous $r_{\text {eff }}=10 \mu \mathrm{m}$ water droplets, solar zenith angle $\theta^{\circ}=60^{\circ}$, and view zenith angle $\theta=45^{\circ}$. The colored (blue and red) areas around the plot of the $2.1 \mu \mathrm{m}$ curve represent photons that have been added or lost near the cloud edges. In this particular case the top reflectance is lower than the side reflectance due to the relative angle between the solar illumination and a vector normal to the side or the top surfaces. The relative angle with the top surface vector is $60^{\circ}$ whereas the angle with the side vector is $30^{\circ}$. The blue line along the surface of the cylinder represents the region where there is saturation and the $2.1 \mu \mathrm{m}$ reflectance from the cylinder equals the plane parallel result with the proper geometry. A point half way along the blue line represents the general place that was selected to construct our 3D-LUT from retrievals away from the cloud edges. Other regions of the cylinder could be used for retrievals closer to cloud base or top.

proach an asymptotic behavior after an optical depth of $\sim 30$ away from the edge. The lack of absorption at $0.66 \mu \mathrm{m}$ increases this distance significantly, enhancing the edge effect (see Marshak et al., 2006). This behavior re-affirms that absorbing wavelengths are less sensitive to 3-D effects due to the shorter photon path inside the cloud. For the same reason, a plane parallel approximation works better for clouds at $2.1 \mu \mathrm{m}$ than at $0.66 \mu \mathrm{m}$. Nevertheless, the plane parallel approximation can also be a good approximation to represent cloud side radiances as long as the correct geometry is taken into account. The solar zenith angle and the view zenith angle must be corrected for the appropriate cloud side geometry. A vector normal to the studied surface is used as a geometrical reference and not necessarily the zenith. Therefore to simulate the side reflectance of a cylinder illuminated with solar zenith angle $\theta_{o}$, and observed from a view zenith angle $\theta$, the plane parallel analogue corresponds to a case with $\theta_{\mathrm{o}-\mathrm{pp}}=\left(90^{\circ}-\theta_{\mathrm{o}}\right)$ and $\theta_{\mathrm{pp}}=\left(90^{\circ}-\theta\right)$. The plane parallel approximation is valid only for modeling cases far away from cloud edges (at least an optical distance 30 from any edge for water droplet $r_{\text {eff }}=10 \mu \mathrm{m}$ ), over dark surface, where side illumination effects caused by the surface albedo are 
negligible. Also, the plane parallel approximation for cloud side radiances is valid for effective radii determinations but not necessarily for $\tau_{z}$ or $\tau_{x}$ retrievals. Marshak et al. (2006) presented more details on this discussion.

The SHDOM simulated cylindrical clouds were used for the generation of retrieval lookup tables to determine the vertical profile of droplet effective radii as a function of the cloud side radiances. For simplicity, the initial retrievals were performed away from cloud edges (avoid the first few pixels near cloud base and top), using LUT radiances coming from the center of cylinders with $\tau_{z}=100$, and aspect ratios $\tau_{z} / \tau_{x}=1,2,3,4$ and 5. The validity of the 3-D cylindrical cloud approach used here was studied by producing a 3-D analog of the Nakajima-King diagrams using side reflectances from the center of the cylinders, at $\lambda=0.66$ and $2.1 \mu \mathrm{m}$ as a function of droplet effective radii, and horizontal optical depth $\tau_{x}$. Figure 5 shows the intercomparison between the Nakajima-King analogs of cylindrical homogeneous clouds versus the stochastic results produced by Marshak et al. (2006). In the later case, the stochastic clouds were composed of complex cloud fields with the 3-D radiative transfer results taking into account shadows and photons traveling between clouds, as well as a complex vertical profile of droplet sizes and thermodynamic phase distribution including, water, mixed phase, and ice. The question to be answered here is the applicability of a simplified cylinder LUT in inverting results from such a complex cloud field. Figure 5 shows that the cylindrical clouds of specific radii produce reflectance at 2.1 and $0.67 \mu \mathrm{m}$ that fall within the ranges of the reflectances produced by the more complex stochastic clouds of the same radii, as indicated by the common color. Note that for the stochastic clouds the different colors each denote a range of sizes spanning 4 or 5 microns with the smallest radii near the top of the range for each color, while the larger colored symbols denote a specific size particle for the cylindrical clouds. Thus when the cylindrical blue dots representing exactly $10 \mu \mathrm{m}$ appear at the upper edge of the cloud of stochastic blue points representing the range of 10-16 $\mu \mathrm{m}$ and the bottom edge of the stochastic red points representing the range $5-10 \mu \mathrm{m}$, it shows how the $10 \mu \mathrm{m}$ cylindrical clouds want to be right on that intersection between 5-10 $\mu \mathrm{m}$ and $10-16 \mu \mathrm{m}$. The figure suggests that retrievals made using the simplified approach could successfully retrieve cloud particle effective radius to within $\pm 1 \mu \mathrm{m}$ of the stochastic model for optically thick clouds. This is sufficient to resolve the vertical profile of droplet and crystal size in a deep convective cloud, as will be demonstrated below. However, for future applications we propose retrievals based on stochastic cloud fields, as in Marshak et al. (2006), or on cloud resolving models, as in Zinner et al. (2008) which use a Bayesian approach (e.g. McFarlane et al., 2002) to provide a distribution of possible effective radii that statistically satisfy to the measured radiances.

As a proof-of-concept for the statistical Bayesian retrieval of the particle size vertical profiles, Zinner et al. (2008) ap-

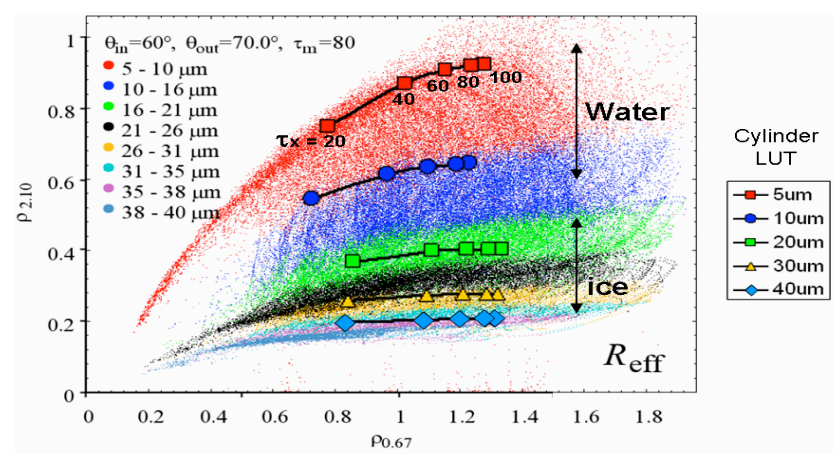

Fig. 5. The collection of colored dots in the background represent the 3-D analog of the plane parallel Nakajima-King type of diagrams for stochastic cloud fields and a variable vertical profile of droplet effective radii, and thermodynamic phase. The overlaid black lines and markers were calculated by individual homogeneous cloud cylinders with total $\tau_{z}=100$, effective radius as shown in the legend, and optical distance aspect ratios of 5, 4, 3, 2, and 1. A combination of ice and water particles were used in both simulations for the cylindrical and for the stochastic cloud fields.

plied the Bayesian approach to simulated cloud fields based on the Goddard Cumulus Ensemble Model (Tao et al., 2003), This cloud resolving model provides complex 3-D structures of ice, water, and mixed clouds from the early stage of convective development to mature deep convection. Zinner et al. (2008) demonstrated that the regardless of the high spatial complexity of realistic cloud structure and 3-D radiative transfer, the signatures of cloud particle effective radii were clearly detectable in the statistical sense.

\subsection{Penetration of the cloud side measurements and the horizontal distribution of the cloud microphysical properties}

Cloud side remote sensing is based on the assumption that the vertical profile of cloud droplet (particles) size retrieved near cloud edges can be extrapolated for the whole cloud at a given temperature or height level. Photons at absorbing wavelengths (e.g. $2.1 \mu \mathrm{m})$ can only profile a physical volume near the cloud edges. By "near cloud edges" we understand the optical distance a "typical" photon at 2.1-2.3 $\mu \mathrm{m}$ wavelength can penetrate inside the cloud (Platnick, 2000; Zinner and Mayer, 2006; Davis and Marshak, 2010). Fortunately, the effective radius of cloud droplets is, perhaps, one of the most conservative microphysical property at a given temperature and the same cloud system (Rosenfeld and Lensky, 1998; French et al., 2000; Freud et al., 2008). Indeed, while both cloud liquid water and droplet concentration vary substantially along a path of a horizontally flying aircraft, the effective radius remains relatively constant (e.g. see Fig. 10 in Rosenfeld and Lensky, 1998 for convective clouds and Figs. 2 and 3 in Blyth and Latham, 1991 for cumulus clouds). In addition to a very comprehensive discussion of 
this phenomenon given by Freud et al. (2008), we only mention that cloud models (Z. Levin, private communications, 2001) also confirm that the assumption of mild fluctuations of the droplet effective radius at a given temperature (or at a given height) looks very realistic. Experimental evidence for this fact can be found in Rosenfeld et al. (2006b) who show the results of aircraft penetrations of convective elements of severe convective storms. The aircraft measured temperature, liquid water content, particle number concentrations, and effective diameter using a hot wire probe and the FSSP. The results show that despite large variations in liquid water content, the effective diameter of the droplets remains nearly constant across the cloud cross section. Similar results, although mostly unpublished, have been observed by D. Rosenfeld who conducted similar in situ aircraft measurement in convective clouds at widely varying conditions in Brazil, Texas, California, Portugal, India and Israel. This serves as strong evidence that the droplet effective radius is a conservative property across convective clouds and can effectively be estimated by measurements from the cloud side.

The assumption that effective radius is constant along a constant altitude can be easily verified by the cloud side remote sensing retrievals themselves. Different near-infrared wavelengths penetrate different distances into a cloud, as measured in optical thickness units (Platnick, 2000, 2001; Chang and Li, 2002, 2003; Zhang et al., 2010). The different penetration distances produce different effective radii when applied to remote sensing of cloud top. This is because effective radius is a strong function of vertical position in the cloud. If different wavelengths are applied to cloud sides, at the same altitude in the cloud, we expect the retrievals to produce the same effective radii, regardless of the different penetration distance from cloud edge. If cloud particle effective radius is found to be not constant for a given altitude over a large statistical sampling of clouds, then this itself will be an important scientific finding.

\section{Data analysis and results of aircraft measurements}

\subsection{Vertical profile of effective radius and thermodynamic phase}

An example of the new type of cloud side measurements presented in Sect. 2.3 is shown in Fig. 6. This figure shows the results of our first aircraft experiment performed during the CLAIM (Cloud Aerosol Interaction Mission) campaign in Brazil, in January/February 2005, testing the cloud scanner prototype. This prototype contained three measurement devices, a spectrometer plus scanning mirror, a thermal scanner and a digital camera with a fisheye lens, each aligned and linked temporally to view the same scene at the same time. The first instrument consists of a scanning mirror, scanning from $+60^{\circ}$ to $-60^{\circ}$, pointed out of the side of the aircraft directing reflected radiance into an Analyti-

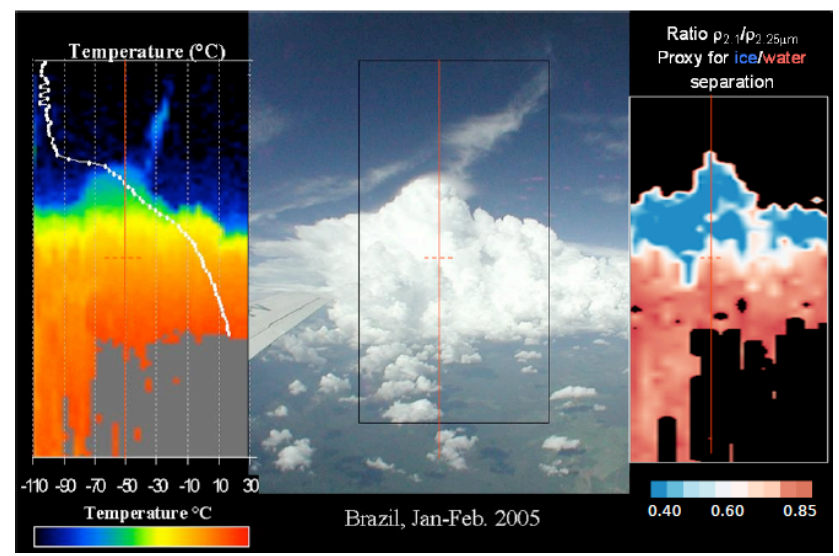

Fig. 6. Cloud side measurements performed with the cloud scanner prototype. The left panel shows the brightness temperature profile, the center panel shows the actual picture of the cloud being observed, and the right panel shows an image of the ratio of reflectances at 2.10/2.25 $\mu \mathrm{m}$, which represents the separation between ice and water particles in the cloud. The white line and dots on the left panel represents the temperature profile. The same solid red line is shown on the center and right panels of the figure. The red dashed horizontal line represents the zero Celsius mark where also the mixed phase starts on the right hand side panel.

cal Spectral Device (ASD) spectrometer, which allowed radiance (reflectance) measurements from $0.35 \mu \mathrm{m}$ to $2.5 \mu \mathrm{m}$ at $0.001 \mu \mathrm{m}$ intervals. The ASD was calibrated using an integrating sphere traceable to NIST standards, at the NASA Goddard Space Flight Center, before and after deployment to Brazil with the resulting absolute radiance calibration to better than $5 \%$. The scanning mirror produces a scan through the $120^{\circ}$ range in $10 \mathrm{~s}$ with a $1^{\circ}$ field of view. As the aircraft flies forward the series of vertical scans produce an image. In conjunction with the spectrometer measurements, a modified Heitronics thermal scanner, aligned with the ASD scanning mirror, measuring emitted radiance at $11 \mu \mathrm{m}$ was used to derive the brightness temperature field of the scanned scene, including vertical temperature profiles of clouds. The modified Heitronics scanner has a $2^{\circ}$ field of view and makes measurements with an accuracy of about $1^{\circ} \mathrm{C}$. The fisheye camera took pictures every $10 \mathrm{~s}$ to record the cloud context. This three component system was mounted on the side window of the Instituto Nacional Pesquisas Espaciais (INPE) Bandeirante aircraft and flown for multiple missions during the rainy season over Brazil, with the primary goal of remote sensing of convective cloud sides.

In Fig. 6 the central panel shows the actual picture of the cloud under study, while the left panel shows the brightness temperature image overlaid by a temperature profile (white plot) in the center of the cloud and the right panel shows the separation between liquid and ice using a technique described below. The spectrometer measurements provide the input for retrievals of droplet effective radius, which use 
calibrated $0.67 \mu \mathrm{m}$ and $2.1 \mu \mathrm{m}$ reflectances measured from the side of convective clouds during the CLAIM campaign, and the simplified cylindrical 3-D look-up-tables described above. For a given pixel of the cloud side, the measured $0.67 \mu \mathrm{m}$ and $2.10 \mu \mathrm{m}$ reflectances point to a unique particle effective radius in the LUT. This value forms an ordered pair with the brightness temperature calculated from the thermal $11 \mu \mathrm{m}$ observation of the same pixel. Plotting temperature on the vertical axis and effective radius on the horizontal axis, we can produce a retrieval of the microphysical profile within the cloud. Two LUTs were employed, one for ice and one for water clouds, with the choice of cloud phase determined by the ratio of 2.1 and $2.25 \mu \mathrm{m}$ reflectances, appearing in the bottom right hand panel of Fig. 7, and explained below. However, the retrieval was not sensitive to the choice of either water or ice LUTs, at the geometries measured during this campaign. Differences between using water or ice LUTs were generally less than $2 \mu \mathrm{m}$. Choice of ice particle shape can have a strong effect on the phase function of certain geometries and affect the retrieval. However, because we did not know the shape and because often multiple shapes occur simultaneously in an ice cloud, we used an average of several available ice microphysical models to create the ice LUT.

Figure 7 (bottom left panel) gives an example of such retrieval showing warm cloud processes near cloud base where droplets grow by diffusion and collision-coalescence, and more efficiently, the mixed phase processes were the droplets grow even faster. The water droplets grew by diffusion and/or collision-coalescence up to about $14 \mu \mathrm{m}$ effective radius and a temperature of about $-11^{\circ} \mathrm{C}$ after which the droplets started to freeze and mixed phase processes dominated the particle growth. The mixed phase process took place till a temperature of about $-37^{\circ} \mathrm{C}$ (respecting the limit of $-38^{\circ} \mathrm{C}$ for the existence of liquid water) causing the droplets to increase up to $37 \mu \mathrm{m}$ effective radius. The ice phase profile shows the particle effective radius decreasing as a function of height, likely due to precipitation processes inside the cloud and/or nucleation of additional small ice crystals. Other cases from the same experiment showed a constant effective radius profile in the ice phase. The droplet size profile shown here and several other results obtained during the CLAIM field campaign are in good agreement with the conceptual models of droplet growth in convective clouds presented by Rosenfeld and Woodley (2003) and Rosenfeld and Lensky (1998) (see Fig. 2). The top panel in Fig. 7 shows a wide angle picture of the cloud under study. Although the cloud morphology in this picture may trick some observers, this cloud is a very deep convective cloud with cloud top temperatures near $-90^{\circ} \mathrm{C}$.

In discussion of the bottom left panel of Fig. 7 we infer information about cloud thermodynamic phase based on slopes of the temperature-effective radius curve (Yuan et al., 2010). A completely independent measurement of the droplet thermodynamic phase is shown in the bottom right panel of Fig. 7 and applied to the entire cloud in the right hand panel of

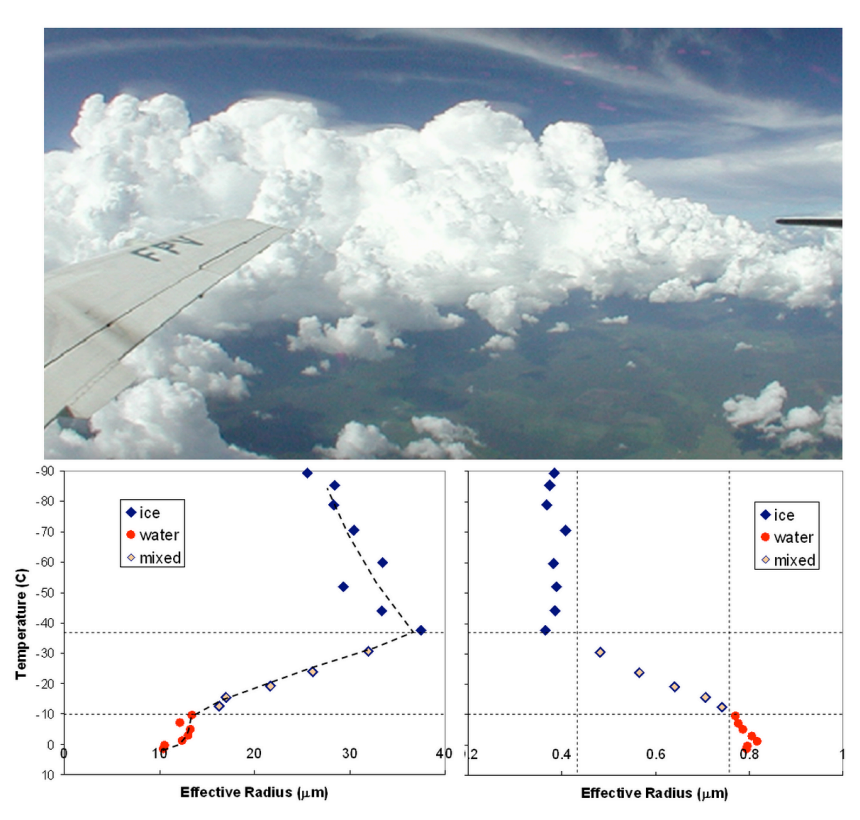

Fig. 7. Effective radius retrieved with radiances from the cloud side (bottom left plot) and separation between ice and water determined by the ratio between reflectances $2.10 / 2.25 \mu \mathrm{m}$ (bottom right plot) as a function of the vertical profile along the cloud side. The top image represents a wide field picture of the cloud system under study.

Fig. 6. These panels show the ratio between reflectances at $2.10 \mu \mathrm{m}$ and $2.25 \mu \mathrm{m}$, which will be explained later in Sect. 3.2 as an indicator of water, ice, or mixed phase present inside the cloud. It is important to notice that the mixed phase identified in the reflectance ratio $2.10 / 2.25 \mu \mathrm{m}$ corresponds unequivocally with the mixed phase droplet growth suggested by the effective radius profile. This apparent agreement once again indicates the power of the cloud side measurements in identifying the cloud microphysical processes inside the cloud, assuming that the profiles at the cloud sides are indicative of those in the cloud's core, as many observations and models suggest. The large amount of information present in this vertical profile potentially increases our understanding of how aerosols may affect clouds and change the precipitation efficiency by driving the droplet growth at the scales where the interaction with the $\mathrm{CCN}$ really happens. Since the freezing temperature depends on the droplet size distribution, which is affected by the aerosol concentration and type, and eventually by the aerosol efficiency to act as ice nuclei, the simple measurement of the cloud thermodynamic phase as a function of the temperature and amount of aerosols can be a good indicator of the interaction between aerosols and clouds. 


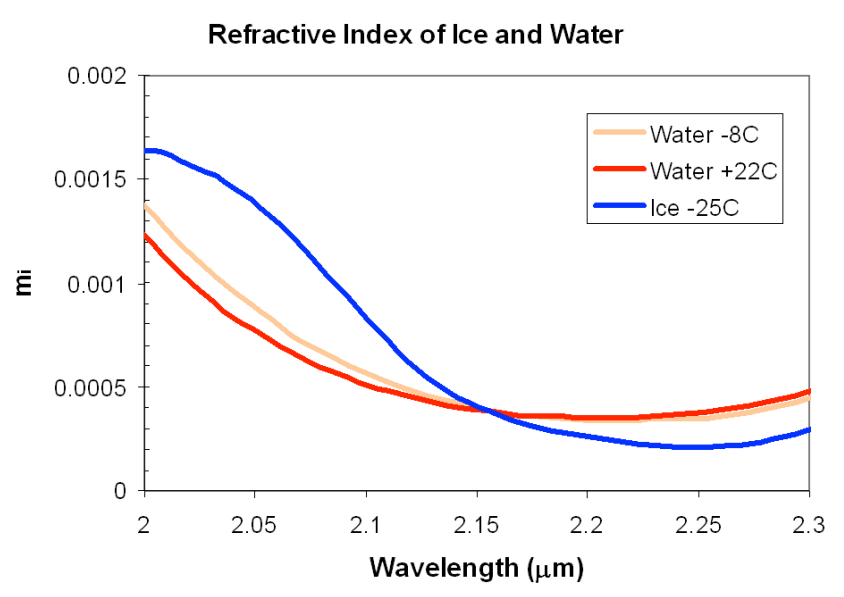

Fig. 8. Data extracted from Kou et al. (1993) shows the spectral dependence of the imaginary component of the refractive indices of ice and water between 2.0 and $2.3 \mu \mathrm{m}$, showing the crossing point around $2.15 \mu \mathrm{m}$. The water case also shows some dependence with temperature.

\subsection{Interpretation of the ice-water thermodynamic phase measurements}

Here we justify the applicability of measurements centered at 2.10 and $2.25 \mu \mathrm{m}$ for the identification of ice, water, and mixed phase on the vertical profiles measured on the side of convective clouds. Figure 8 illustrates that the primary signal separating ice and water in these wavelengths comes from the imaginary component of the refractive index. Ice and water have sufficiently different refractive indices at 2.10 and $2.25 \mu \mathrm{m}$ that allow us to identify them by simply taking the ratio between the reflectances at these two wavelengths. In addition, we see that the refractive index at these wavelengths is also a weak (but significant) function of the water temperature.

In order to evaluate the power of the ice-water separation algorithm on the vertical profile of complex convective clouds, we used the SHDOM code to simulate radiation reflected from cylindrical clouds with microphysical vertical profile following the conceptual diagram of Fig. 1. The conceptual diagram used is shown in Fig. 9a illustrating 5 microphysical stages as a function of the temperature or height inside the clouds. Initially the droplets grow by water vapor diffusion, followed by collision-coalescence, a third stage where the droplets have already reached large enough sizes to enable internal precipitation processes, a mixed phase where ice and water can coexist and further enhance the droplet growth efficiency, and a glaciated stage where all the droplets are frozen. The ice particles were simulated using 5 different ice habits and phase functions proposed by Yang et al. (2000). The Rosenfeld and Woodley (2003) diagrams suggest that at the glaciated stage, the effective radius remain constant as a function of height. Our observations (e.g.

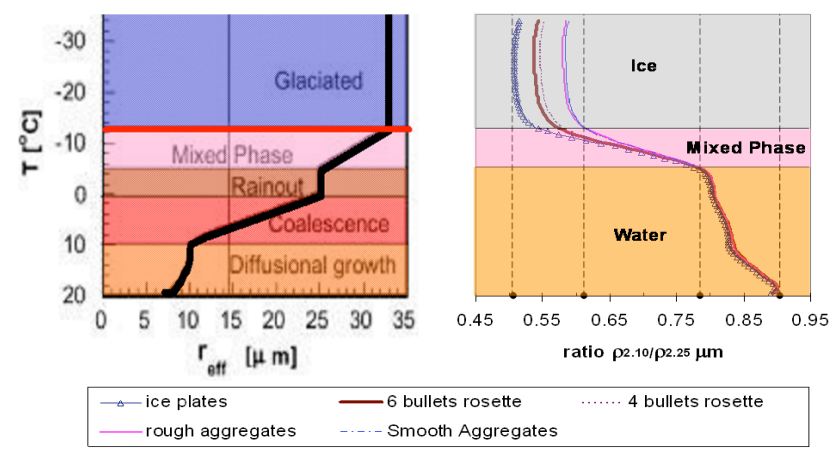

Fig. 9. (a) Adapted from Rosenfeld and Woodley (2003 - Fig. 1) shows the "general case" effective radius and thermodynamic profile used here for the SHDOM simulation. (b) SHDOM simulation of the reflectance ratios $(2.10 / 2.25 \mu \mathrm{m})$ based on a cylindrical cloud with a complex profile of particle effective radii and thermodynamic phase showing the sensitivity of this ratio to the presence of water, ice, and mixed phase.

Fig. 7 above) show several cases where the particle size at this stage even decreases as a function of height. The cloud side radiances for this model were calculated for $60^{\circ}$ solar zenith angle, $50^{\circ}$ view zenith angle, and were used to simulate the 2.10/2.25 $\mu \mathrm{m}$ ratio. The results are shown in Fig. 9b, where water droplets show ratio values between 0.78 to 0.9 , depending mainly on droplet size effects, and ice particles show ratios between 0.5 and 0.61 . It is important to notice that the $2.10 / 2.25 \mu \mathrm{m}$ reflectance ratio is also sensitive to different ice crystal habits, identified by the different colored curves. The dependence of the 2.10/2.25 $\mu \mathrm{m}$ reflectance ratio on the cloud droplet size and temperature produces some broadening on the final results but, the separation between ice, water, and mixed phase still produces very strong and unambiguous signals.

Experimental measurements of the $2.10 / 2.25 \mu \mathrm{m}$ reflectance ratio were performed for several convective clouds (observed during the CLAIM campaign) after separating the water and ice portions of the clouds. The separation was done using the measured brightness temperatures. Clouds and portions of clouds with brightness temperatures warmer than $0^{\circ} \mathrm{C}$ were obviously water. Clouds and portions of clouds with temperatures colder than $-38^{\circ} \mathrm{C}$ were obviously ice. The thermal range in which mixed phase might occur were avoided. Only clouds uniformly illuminated, with scattering angles at the observed pixels close to $180^{\circ}$ were considered, and any remaining shadows were filtered out. Figure 10 shows histograms of the reflectance ratios where the ice values vary from 0.33 to 0.47 , and the reflectance ratios for water varied from 0.75 to 0.95 . The distribution of ratio values for water agrees well with the simulated values shown in Fig. 9 (above) plus the dependence of the imaginary refractive index with temperature that was presented in Fig. 8. For ice, on the other hand, the experimental values are well 
below the simulated values made over five different crystal habits with random orientation, from ice plates to rosettes and aggregates. The differences cannot be explained by the particle size effect alone because in Fig. 7 the 2.1/2.25 $\mu \mathrm{m}$ ratio remains constant with height over the entire range of the ice portion of the cloud, despite there being a range of $10 \mu \mathrm{m}$ in particle radius. For constant geometry, the ratio is only sensitive to refractive index. While there is no conclusive proof, the fact that the simulations do not match the experimental evidence suggests that the refractive index value for ice shown in Fig. 8 is not correct for the ice clouds measured during this experiment.

For clouds simulated by the Goddard Cumulus Ensemble Model (Tao et al., 2003), Zinner et al. (2008) were able to successfully discriminate between ice and water clouds using the 2.10 to $2.25 \mu \mathrm{m}$ reflectance ratio. By comparing to the "true" thermodynamic phase as the model output, they determined an optimal threshold: if the ratio is larger than 0.75 , the cloud is water, if the ratio is smaller than 0.6, the cloud is ice, while in-between, the cloud thermodynamic phase is uncertain and corresponds to a mixed phase.

In order to show the sensitivity of the reflectance ratio to the imaginary refractive indices of water and ice at the 2.10 and $2.25 \mu \mathrm{m}$, Fig. 10 also shows the ratio:

$\alpha=\frac{1 / m_{i \_2.10 \mu \mathrm{m}}}{1 / m_{i \_2.25 \mu \mathrm{m}}}$

where $m_{i}$ is the imaginary part of the refractive index at each wavelength. The results for $\alpha$ are shown in the overlaid vertical lines in Fig. 10. Although the refractive index ratio is not exactly the same as the reflectance ratio, this comparison shows in simple terms the effect of the spectral refractive indices of water and ice.

\section{Suggested satellite observations of cloud side radiances}

Following the cloud side measurement concepts described above, a potential satellite mission (Cloud Aerosol Interaction Mission in 3-D, or CLAIM-3D) is proposed with the primary goal of measuring the vertical profile of cloud droplet effective radius, thermodynamic phase, brightness temperature, and, by adding aerosol measurements to the system, we offer the possibility of statistically observing cloud response to the type and amount of aerosol particles surrounding the cloud field. The measurements must be done in cirrus free pixels where the illuminated side of a convective cloud can be observed. Figure 11 shows a schematic diagram for the CLAIM-3D satellite concept. The cloud side measurements should be composed of enough visible and shortwave infrared measurements to provide effective radius and particle phase retrievals, as well as thermal infrared wavelengths to provide brightness temperature retrievals. Combination between thermodynamic phase and brightness temperature

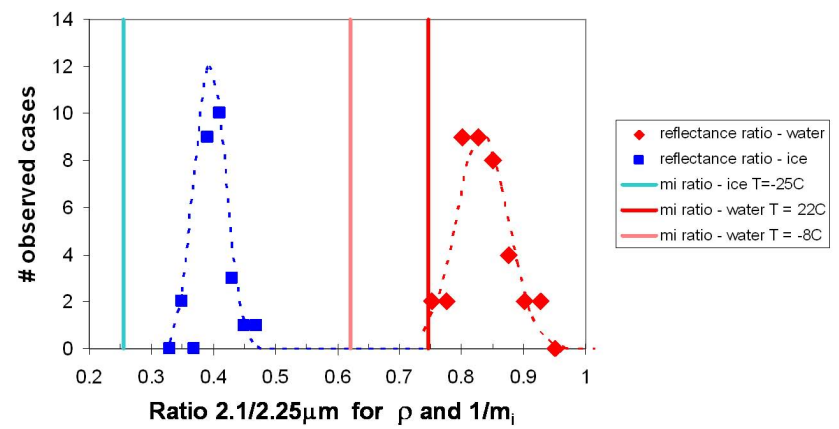

Fig. 10. Histograms of experimental measurements of the reflectance ratio $\rho_{2.10} / \rho_{2.25} \mu \mathrm{m}$ for ice and water clouds. The red dots show results for the water portion of convective clouds and the blue dots for the ice component. The vertical lines show ratios of the $\left(1 / m_{i}\right)$ factor for the same wavelength ratio, where $m_{i}$ is the imaginary component of the refractive indices of water (red colors for 2 different temperatures) and ice (blue).

has key importance in revealing detailed microphysical processes inside the clouds. Multi-angle observations would provide parallax measurements helping even further to reveal details of the cloud structure. Spatial resolution must be small enough to provide profiling information on convective clouds, but due to the general diffuse properties of clouds and the radiative smoothing scale (Marshak et al., 1995), there should be not much benefit of spatial resolutions better than $100 \mathrm{~m}$ (Rosenfeld et al., 2004). Zinner et al. (2008) showed in simulations of realistic cloud fields that with a pixel footprint of $250 \mathrm{~m}$ one can use the cloud scanner system discussed in this work to accurately retrieve profiles of cloud droplet sizes and thermodynamic phase. The observation geometry of the satellite must be optimized as a function of the solar illumination and the scattering angle geometry, minimizing shadows and other undesirable 3-D effects. The most optimized geometry for cloud side observation is to point the sensor close to the direction of the sun vector at times and locations of relatively large solar zenith angles (preferably $>40^{\circ}$ ). An ideal data set can be equally acquired with a cross track push broom or snapshot imagers centered in this geometry. As discussed in Sect. 2.3 and Fig. 3 above, high altitude aircrafts or satellites actually provide the best observation geometry for cloud side measurements allowing for constant view angle observations from above the clouds, which further simplifies the retrieval algorithm. Side observations of deep convective clouds from low flying aircraft flying on the side of the clouds (as presented in Fig. 2) have the worst case scenario because the measurements are performed over a large range of viewing angles with mixtures of shadowed geometries.

In addition to the cloud side measurements it is advantageous to provide high quality aerosol retrievals including accurate spectral optical depth and information on size distribution. We will not discuss concepts for advanced aerosol 


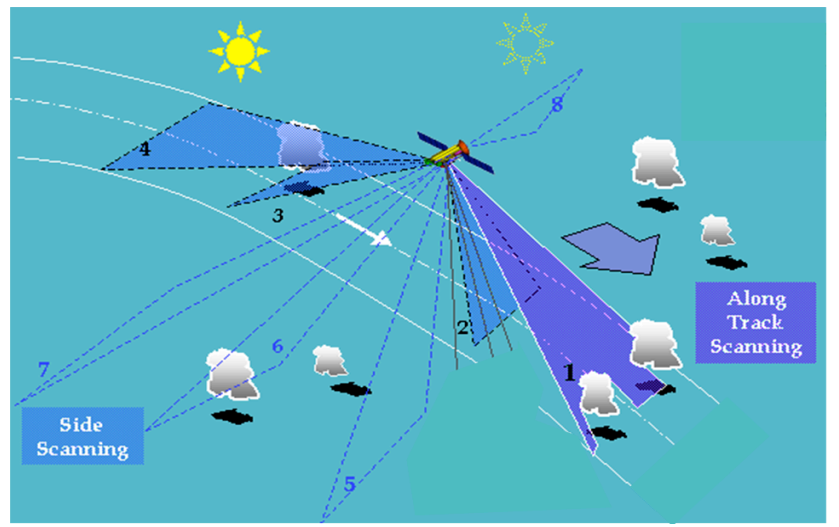

Fig. 11. Conceptual design of a 3-D Cloud Aerosol Interaction Mission satellite (CLAIM-3D) specially designed to perform detailed measurements of aerosols particles and its influences on cloud microphysical properties and on the onset of precipitation.

retrievals here, nor will we discuss the difficulties and mitigation strategies for retrieving aerosol in proximity to clouds. We will only mention that a comprehensive set of aerosol parameters can be obtained with a combination of multiangle, wide wavelength range (from UV or visible to $2.3 \mu \mathrm{m}$ ), and polarization measurements (Mishchenko et al., 2007). Although the CCN concentration cannot be directly measured from space, the combination between accurate optical depth, aerosol particle size information and possibly refractive index retrievals can provide important proxies to the concentration and type of CCNs available in a given cloud field (Andreae, 2009). Rosenfeld (2006b) pointed out that the multi-angle polarization measurements by POLDER and the proposed Aerosol Polarimetry Sensor (APS) that was to fly on Glory and may be rescheduled, significantly improve our ability to obtain proxies for $\mathrm{CCN}$ aerosols from space, emphasizing particle size and refractive index (for proxy of amount of absorbed water) as their main characteristic. Other highly accurate imaging polarimeter sensors with hyper angular capability (e.g. the HARP - Hyper Angular Rainbow Polarimeter) have been developed for space applications and will be available for such measurements. We will also mention that polarization offers the possibility of retrieving aerosol information even in a pixel with subpixel clouds (Hasekamp, 2010), and there have been demonstrations of associations between aerosols and clouds that are sufficiently robust so that cloud effects in the aerosol product do not affect the conclusions of the analysis (Koren et al., 2010a).

The CLAIM-3D mission will build upon the experience of previous space missions combining comprehensive cloud microphysical measurements with advanced aerosol retrievals providing information on relationships between aerosols and detailed cloud microphysical structure that should help explain how the aerosol particles are affecting cloud micro- physics, thermodynamics, and the processes that precede precipitation. The data interpretation would be directly guided by the brightness temperature measurements, and its derivative with respect to the position of the satellite $(-d T / d x)$. This variable, provides the key to determine if the measured pixel corresponds to cloud top, cloud side, and how stiff are the slopes of the cloud edges. The stochastic/Bayesian approach proposed by Zinner et al. (2008) and Marshak et al. (2006) provides the needed tools to determine the effective radius profile and variance that best fit the measured radiances. With aerosol retrievals added to the measurements presented here, the CLAIM-3D concept provides a full set cloud microphysical parameters with collocated measures of aerosol properties that significantly improves today's state of the art knowledge on the interactions between aerosol particles and cloud properties.

\section{Summary and discussion}

The methodology discussed here consists of passively measuring solar radiation photons reflected and emitted by the cloud sides to provide the vertical profile of cloud microphysical and thermodynamical properties, which can be coupled to aerosol measurements to understand how these cloud properties change as a function of the aerosol type and amount around the cloud field. Cloud side measurements provide a powerful tool to unravel the effect of aerosol particles in changing cloud microphysics, lifetime, dynamics, thermodynamics, phase and the onset of precipitation. These observations can be performed from ground, aircraft, or satellite. For the best geometry, observations from above the clouds, using high altitude aircraft or satellite sensors would be preferable.

The measurements provide:

- A snapshot of the vertical structure of cloud microphysics and thermodynamic phase, as a function of height, or of the brightness temperature profile from the side of the clouds.

- The possibility of obtaining large statistics to allow confident conclusions about the physical processes inside the cloud, and how they are affected by the presence, amount, and type of aerosol particles.

These two conditions cannot be met today by existing remote sensing at the required resolution for resolving convective clouds except for the largest and deepest ones, as shown in Rosenfeld and Lensky (1998). In situ measurements are also unable to provide these capabilities. These results, in conjunction with other measurements of cloud and aerosol characteristics will improve our understanding of the factors influencing cloud development, and the onset and character of precipitation. Results of 3-D radiative transfer simulations in this work and in Marshak et al. (2006) and Zinner 
et al. (2008) papers show the large sensitivity of the cloud side radiances to effective radius, and thermodynamic phase of the cloud particles. We must use this sensitivity to reveal important details of cloud microphysics, and better support the development and validation of cloud modeling activities.

While retrievals of cloud microphysical profiles from cloud side measurements offer new possibilities in measuring and understanding cloud development, the method has limitations. The passive sensor must have an unobstructed view of the illuminated side of the cloud, and the sensor must have sufficient spatial resolution to resolve the vertical structure of the target cloud. Anticipating a spatial resolution of approximately $200 \mathrm{~m}$ from a space instrument, this suggests the method will work best for the example shown in this paper, an isolated convective cloud. Shallow stratus clouds or complex multi-layer frontal systems will prove to be more difficult. The method is also limited by its assumptions, most importantly that the profile retrieved from near the cloud edge is characteristic of the profile evolving in the cloud core. We do not negate the seriousness of this assumption, but we are heartened by a growing body of literature that demonstrates over and over again using observations and modeling that while other parameters vary in the horizontal, cloud particle effective radius remains nearly constant along a given altitude from edge through cloud center (Rosenfeld and Lensky, 1998; Freud et al., 2008; Blyth and Latham, 2001; Rosenfeld and Woodley 2006b).

The CLAIM-3D satellite concept proposed here combines several techniques to simultaneously measure the vertical profile of cloud microphysics, thermodynamic phase, and brightness temperature, which can be coupled to measurements of aerosol amount and type in the neighborhood of the clouds. The wide wavelength range, and the use of multiangle polarization measurements proposed for this mission would allow us to estimate the availability and characteristics of aerosol particles acting as cloud condensation nuclei, and their effects on the cloud microphysical structure. These results would provide unprecedented details on the response of cloud droplet microphysics to natural and anthropogenic aerosols at the scale where the interaction really happens.

Acknowledgements. This work was partially supported by NASA Goddard Space Flight Center New Opportunities Office. We thank Keith Gendreau, Juan Carlos Ceballos, Karla Longo and Gilberto K. Nishioka for the essential help in collecting the aircraft data, and the CPTEC/INPE support on weather forecast during the CLAIM-2005 campaign in Brazil. P. Artaxo acknowledges financial support from $\mathrm{CNPq}$ and FAPESP. We also thank Graham Feingold, Anthony Davis, Bernhard Mayer, Steve Platnick and Zev Levin for the numerous stimulating discussions on this subject.

Edited by: R. von Glasow

\section{References}

Ackerman, A. S., Toon, O. B., Stevens, D. E., Heymsfield, A. J., Ramanathan, V., and Welton, E. J.: Reduction of tropical cloudiness by soot, Science, 288, 1042-1047, 2000.

Albrecht, B. A.: Aerosols, cloud microphysics, and fractional cloudiness, Science, 245, 1227-1230, 1989.

Andreae, M. O.: Correlation between cloud condensation nuclei concentration and aerosol optical thickness in remote and polluted regions, Atmos. Chem. Phys., 9, 543-556, doi:10.5194/acp-9-543-2009, 2009.

Andreae, M. O., Rosenfeld, D., Artaxo, P., Costa, A. A., Frank, G. P., Longo, K. M., and Silva-Dias, M. A. F.: Smoking rain clouds over the Amazon, Science, 303, 1337-1342, 2004.

Andreae, M. O., Artaxo, P., Barrie, L. A., Brsenguier, J. L., Cotton, W. R., Feingold, G., G. Sunling L., Hegg, D. A., Kauffman, Y. (Deceased), Levin, Z., Lohmann, U., Tanre, D., and Yuter, S.: The WMO/IUGG International Aerosol Precipitation Science Assessment Group (IAPSAG) Aerosol Pollution Impact on Precipitation: A Scientific Review, edited by: Levin, Z. and Cotton, W., Springer Verlag, ISBN 978-1-4020-8689-2, 2008.

Blyth, A. M. and Latham, J.: A climatological parameterization for cumulus clouds, J. Atmos. Sci., 48, 2367-2371, 1991.

Chang, F.-L. and Li, Z.: Estimating the vertical variation of cloud droplet effective radius using multispectral nearinfrared satellite measurements, J. Geophys. Res., 107, 4257, doi:10.1029/2001JD000766, 2002.

Chang, F.-L. and Li, Z.: Retrieving vertical profiles of water-cloud droplet effective radius: Algorithm modification and preliminary application, J Geophys. Res., 108, 4763, doi:10.1029/2003JD003906, 2003.

Clothiaux, E. E., Moran, K. P., Martner, B. E., Ackerman, T. P., Mace, G. G., Uttal, T., Mather, J. H., Widener, K. B., Miller, M. A., and Rodriguez, D. J.: The Atmospheric Radiation Measurement Program cloud radars: Operational modes, J. Atmos. Oceanic Technol., 16, 819-827, 1999.

Cotton, W. R.: Atmospheric Thermodynamics and Microphysiscs of Clouds, AT620 Lecture Notes, Summer 2005 revision, 2005.

Davis A. B. and Marshak, A.: Solar radiation transport in the cloudy atmosphere: A 3-D perspective on observations and climate impacts, Reports on Progress in Phys., 73, 026801, doi:10.1088/0034-4885/73/2/026801, 2010.

Diner, D. J., Beckert, J. C., Reilly, T. H., Bruegge, C. J., Conel, J. E., Kahn, R., Martonchik, J. V., Ackerman, T. P., Davies, R., Gerstl, S. A. W., Gordon, H. R., Muller, J.-P., Myneni, R., Sellers, R. J., Pinty, B., and Verstraete, M. M.: Multi-angle Imaging SpectroRadiometer (MISR) description and experiment overview, IEEE T. Geosci. Remote Sens., 36(4), 1072-1087, 1998.

Evans, K. F.: The Spherical Harmonics Discrete Ordinate Method for Three-Dimensional Atmospheric Radiative Transfer, J. Atmos. Sci., 55, 429-446, 1998.

Evans, K. F. and Marshak, A.: Numerical Methods in ThreeDimensional Radiative Transfer, in: Three-Dimensional Radiative Transfer in Cloudy Atmospheres, edited by: Marshak, A. and Davis, A. B., Springer, 243-282, 2005.

Fan, J., Yuan, T., Comstock, J. M., Ghan, S., Khain, A., Leung, L. R., Li, Z., Martins, V. J., and Ovchinnikov, M.: Dominant role by vertical wind shear in regulating aerosol effects on deep convective clouds, J. Geophys. Res., 114, D22206, doi:10.1029/2009JD012352, 2009. 
Forster, P., Ramswamy, V., Artaxo, P., Berntsen, T., Betts, R. A., Fahey, D. W., Haywood, J., Lean, J., Lowe, D. C., Myhre, G., Nganga, J., Prinn, R., Raga, G., Schulz, M., and Van Dorland, R.: Changes in Atmospheric Constituents and Radiative Forcing. Chapter 2 of the Climate Change 2007: The Physical Science Basis, IPCC - Intergovernmental Panel on Climate Change Book, Cambridge University Press, United Kingdom, ISSN 9780-521-88009-1, 2007.

French, J. R., Vali, G., and Kelly, R. D.: Observations of microphysics pertaining to the development of drizzle in warm, shallow cumulus clouds, Q. J. Roy. Meteorol. Soc., 126, 415-443, 2000.

Freud, E., Rosenfeld, D., Andreae, M. O., Costa, A. A., and Artaxo, P.: Robust relations between $\mathrm{CCN}$ and the vertical evolution of cloud drop size distribution in deep convective clouds, Atmos. Chem. Phys., 8, 1661-1675, doi:10.5194/acp-8-1661-2008, 2008.

Frisch, A. S., Fairall, C. W., and Snider, J. B.: Measurement of stratus cloud and drizzle parameters in ASTEX with a Ka-band Doppler radar and a microwave radiometer, J. Atmos. Sci., 52, 2788-2799, 1995.

Hansen, J., Sato, M., and Ruedy, R.: Radiative forcing and climate response, J. Geophys. Res., 102, 6831-6864, 1997.

Hasekamp, O. P.: Capability of multi-viewing-angle photopolarimetric measurements for the simultaneous retrieval of aerosol and cloud properties, Atmos. Meas. Tech., 3, 839-851, doi:10.5194/amt-3-839-2010, 2010.

Holben, B. N., Eck, T. F., Slutsker, I., Tanre, D., Buis, J. P., Setzer, A., Vermote, E., Reagan, J. A., Kaufman, Y. J., Nakajima, T., Lavenu, F., Jankowiak, I., and Smirnov, A.: AERONET - A federated instrument network and data archive for aerosol characterization, Remote Sens. Environ., 66, 1-16, 1998.

Kaufman, Y. J. and Koren, I.: Smoke and Pollution Aerosol Effect on Cloud Cover, Science, 313, 655-658, doi:10.1126/science.1126232, 2006.

Kaufman, Y. J., Koren, I., Remer, L. A., Rosenfeld, D., and Rudich, Y.: The Effect of Smoke, Dust and Pollution Aerosol on Shallow Cloud Development Over the Atlantic Ocean, P. Natl. Acad. Sci., 102(32), 11207-11212, 2005.

Khain, A. P. and Lynn, B.: Simulation of a supercell storm in clean and dirty atmosphere using weather research and forecasting model with spectral bin microphysics, J. Geophys. Res., 114, D19209, doi:10.1029/2009JD011827, 2009.

Khain, A. P., Rosenfeld, D., and Pokrovsky, A.: Simulation of deep convective clouds with sustained supercooled liquid water down to $-37.5^{\circ} \mathrm{C}$ using a spectral microphysics model, Geophys. Res. Lett., 28, 3887-3890, 2001.

Khain, A. P., Rosenfeld, D., and Pokrovsky, A.: Aerosol impact on the dynamics and microphysics of convective clouds, Q. J. Roy. Meteorol. Soc., 131, 2639-2663, 2005.

Koren, I., Kaufman, Y. J., Remer, L. A., and Martins, J. V.: Measurement of the Effect of Amazon Smoke on Inhibition of Cloud Formation, Science, 303, 1342-1345, 2004.

Koren, I., Kaufman, Y. J., Rosenfeld, D., Remer, L. A., and Rudich, Y.: Aerosol invigoration and restructuring of Atlantic convective clouds. Geophys. Res. Lett., 32, LI4828, doi:10.1029/2005GL023187, 2005.

Koren, I., Martins, J. V., Remer, L. A., and Afargan, H.: Smoke invigoration versus inhibition of clouds over the Amazon, Science,
321, 946-949, 2008.

Koren, I., Feingold, G., and Remer, L. A.: The invigoration of deep convective clouds over the Atlantic: aerosol effect, meteorology or retrieval artifact?, Atmos. Chem. Phys., 10, 8855-8872, doi:10.5194/acp-10-8855-2010, 2010a.

Koren, I., Remer, L. A., Altaratz, O., Martins, J. V., and Davidi, A.: Aerosol-induced changes of convective cloud anvils produce strong climate warming, Atmos. Chem. Phys., 10, 5001-5010, doi:10.5194/acp-10-5001-2010, 2010b.

Kou, L., Labrie, D., and Chylek, P.: Refractive indices of water and ice in the 0.65- to 2.5um spectral range, Appl. Optics, 32, 3531-3540, 1993.

Lensky, I. M. and Rosenfeld, D.: The time-space exchangeability of satellite retrieved relations between cloud top temperature and particle effective radius, Atmos. Chem. Phys., 6, 2887-2894, doi:10.5194/acp-6-2887-2006, 2006.

Lohmann, U.: A glaciation indirect aerosol effect caused by soot aerosols, Geophys. Res. Lett., 29, doi:10.1029/2001GL014357, 2002.

Marshak, A., Davis, A., Wiscombe, W., and Cahalan, R. F.: Radiative smoothing in fractal clouds, J. Geophys. Res.-Atmos., 100, 26247-26261, 1995.

Marshak, A., Martins, J. V., Zubko, V., and Kaufman, Y. J.: What does reflection from cloud sides tell us about vertical distribution of cloud droplet sizes?, Atmos. Chem. Phys., 6, 5295-5305, doi:10.5194/acp-6-5295-2006, 2006.

McFarlane, S. A., Evans, K. F., and Ackerman, A. S.: A Bayesian algorithm for the retrieval of liquid water properties from microwave radiometer and millimiter radar data, J. Geophys. Res., 107, 4317, doi:10.1029/2001JD001011, 2002.

McFiggans, G., Artaxo, P., Baltensperger, U., Coe, H., Facchini, M. C., Feingold, G., Fuzzi, S., Gysel, M., Laaksonen, A., Lohmann, U., Mentel, T. F., Murphy, D. M., O’Dowd, C. D., Snider, J. R., and Weingartner, E.: The effect of physical and chemical aerosol properties on warm cloud droplet activation, Atmos. Chem. Phys., 6, 2593-2649, doi:10.5194/acp-6-2593-2006, 2006.

McGraw, R. and Liu, Y.: Kinetic Potential and Barrier Crossing: A Model for Warm Cloud Drizzle Formation, Phys. Rev. Lett., 90, 1851-1854, 2003.

Mishchenko, M. I., Cairns, B., Kopp, G., Schueler, C. F., Fafaul, B. A., Hansen, J. E., Hooker, R. J., Itchkawich, T., Maring, H. B., and Travis, L. D.: Precise and accurate monitoring of terrestrial aerosols and total solar irradiance: Introducing the Glory mission, B. Am. Meteorol. Soc., 88, 677-691, doi:10.1175/BAMS88-5-677, 2007.

Nakajima, T. Y. and King, M. D.: Determination of the optical thickness and effective particle radius of clouds from reflected solar radiation measurements - Part I, Theory, J. Atmos. Sci., 47, 1878-1893, 1990.

Nakajima, T., King, M. D., Spinhirne, J. D., and Radke, L. F.: Determination of the optical thickness and effective particle radius of clouds from reflected solar radiation measurements. Part II: Marine stratocumulus observations, J. Atmos. Sci., 48, 728-750, 1991.

Pilewskie, P. and Twomey, S.: Discrimination of ice from water in clouds by optical remote sensing, Atmos. Res., 21, 113-122, 1987a.

Pilewskie, P. and Twomey, S.: Cloud phase discrimination by re- 
flectance measurements near 1.6 and $2.2 \mathrm{~mm}$, J. Atmos. Sci., 44, 3419-3421, 1987b.

Platnick, S.: Vertical photon transport in cloud remote sensing problems, J. Geophys. Res., 105(D18), 22919-22935, 2000.

Platnick, S.: Approximations for horizontal transport in cloud remote sensing problems, J. Quant. Spectrosc. Ra., 68, 75-99, 2001.

Platnick, S., King, M. D., Ackerman, S. A., Menzel, W. P., Baum, B. A., Riedi, J. C., and Frey, R. A.: The MODIS cloud products: Algorithms and examples from Terra, IEEE T. Geosci. Remote Sens., 41(2), 459-473, 2003.

Prenni, A. J., Petters, M. D., Kreidenweis, S. M., Heald, C. L., Martin, S., Artaxo, P., Garland, R. M., Wollny, A. G., and Pöschl, U.: Relative roles of biogenic emissions and Saharan dust as ice nuclei in the Amazon basin, Nature Geosci., 2, 402-405, doi:10.1038/ngeo517, 2009.

Ramanathan, V., Crutzen, P. J., Kiehl, J. T., and Rosenfeld, D.: Aerosols, Climate and the Hydrological Cycle, Science, 294, 2119-2124, 2001.

Rosenfeld, D.: TRMM observed first direct evidence of smoke from forest fires inhibiting rainfall, Geophys. Res. Lett., 26, 31053108, 1999.

Rosenfeld, D.: Suppression of rain and snow by urban and industrial air pollution, Science, 287, 1793-1796, 2000.

Rosenfeld D.: Aerosol-Cloud Interactions Control of Earth Radiation and Latent Heat Release, Space Sci. Rev., 125, 149-157, doi:10.1007/s11214-006-9053-6, 2006a.

Rosenfeld, D.: Aerosols, Clouds, and Climate, Science, 312, 13231324, 2006b.

Rosenfeld, D. and Lensky I. M.: Spaceborne sensed insights into precipitation formation processes in continental and maritime clouds, B. Am. Meteorol. Soc., 79, 2457-2476, 1998.

Rosenfeld D. and Ulbrich, C. W.: Cloud microphysical properties, processes, and rainfall estimation opportunities, Chapter 10 of "Radar and Atmospheric Science: A Collection of Essays in Honor of David Atlas", edited by: Wakimoto, R. M. and Srivastava, R., Meteor. Monogr., 52, 237-258, AMS, 2003.

Rosenfeld, D. and Woodley, W. L.: Deep Convective Clouds with Sustained Supercooled Liquid Water Down to $-37.5^{\circ} \mathrm{C}$, Nature, 405, 440-442, 2000.

Rosenfeld, D. and Woodley, W. L.: Closing the 50-year circle: From cloud seeding to space and back to climate change through precipitation physics. Chapter 6 of "Cloud Systems, Hurricanes, and the Tropical Rainfall Measuring Mission (TRMM)", edited by: Tao, W.-K. and Adler, R. F., Meteor. Monogr., 51, 234 pp., 59-80, AMS, 2003.

Rosenfeld, D., Rudich, Y., and Lahav, R.: Desert dust suppressing precipitation - a possible desertification feedback loop, P. Natl. Acad. Sci., 98, 5975-5980, 2001.

Rosenfeld, D., Lahav, R., Khain, A. P., and Pinsky, M.: The role of sea-spray in cleansing air pollution over ocean via cloud processes, "Research Article", Science, 297, 1667-1670, 2002.

Rosenfeld, D., Cattani, E., Melani, S., and Levizzani, V.: Considerations on daylight operation of $1.6 \mu \mathrm{m}$ vs $3.7 \mu \mathrm{m}$ channel on NOAA and METOP Satellites, B. Am. Meteorol. Soc., 85, 873881, 2004.

Rosenfeld, D., Kaufman, Y. J., and Koren, I.: Switching cloud cover and dynamical regimes from open to closed Benard cells in response to the suppression of precipitation by aerosols, At- mos. Chem. Phys., 6, 2503-2511, doi:10.5194/acp-6-2503-2006, 2006a.

Rosenfeld, D., Woodley, W. L., Krauss, T. W., and Makitov, V.: The Structure of Severe Convective Storms in Mendoza, Argentina, J. Appl. Meteor., 45, 1261-1281, 2006 b.

Rosenfeld, D., Fromm, M., Trentmann, J., Luderer, G., Andreae, M. O., and Servranckx, R.: The Chisholm firestorm: observed microstructure, precipitation and lightning activity of a pyro-cumulonimbus, Atmos. Chem. Phys., 7, 645-659, doi:10.5194/acp-7-645-2007, 2007.

Rosenfeld, D., Lohmann, U., Raga, G. B., O’Dowd, C. D., Kulmala, M., Fuzzi, S., Reissell, A., and Andreae, M. O.: Flood or Drought: How Do Aerosols Affect Precipitation?, Science, 321, 1309-1313, 2008a.

Rosenfeld, D., Woodley, W. L., Lerner, A., Kelman, G., and Lindsey, D. T.: Satellite detection of severe convective storms by their retrieved vertical profiles of cloud particle effective radius and thermodynamic phase, J. Geophys. Res., 113, D04208, doi:10.1029/2007JD008600, 2008b.

Rosenfeld, D., Woodley, W. L., Axisa, D., Freud, E., Hudson, J. G., and Givati, A.: Aircraft measurements of the impacts of pollution aerosols on clouds and precipitation over the Sierra Nevada, J. Geophys. Res., 113, D15203, doi:10.1029/2007JD009544, 2008c.

Rudich, Y., Rosenfeld, D., and Khersonsky, O.: Treating clouds with a grain of salt, Geophys. Res. Lett., 29(22), 2060, doi:10.1029/2002GL016055, 2002.

Stephens, G. L., Vane, D. G. , Boain, R. J., Mace, G. G., Sassen, K., Wang, Z., Illingworth, A. J., O’Connor, E. J., Rossow, W. B., Durden, S. L., Miller, S. D., Austin, R. T., Benedetti, A., Mitrescu, C., and the CloudSat Science Team: The CloudSat mission and the A-Train, B. Am. Meteorol. Soc., 83, 1771-1790, 2002.

Stephens, G. L., Vane, D. G., Tanelli, S., Im, E., Durden, S., Rokey, M., Reinke, D., Partain, P., Mace, G. G., Austin, R., L'Ecuyer, T., Haynes, J., Lebsock, M., Suzuki, K., Waliser, D., Wu, D., Kay, J., Gettelman, A., Wang, Z., and Marchand, R.: The CloudSat mission: Performance and early science after the first year of operation, J. Geophys. Res., 113, D00A18, doi:10.1029/2008JD009982, 2008.

Suzuki, K., Nakajima, T. Y., and Stephens, G. L.: Particle growth and drop collection efficiency of warm clouds as inferred from joint CloudSat and MODIS observations, J. Atmos. Sci., 67, 3019-3032, doi:10.1175/2010JAS3463.1, 2010.

Tao, W.-K., Simpson, J., Baker, D., Braun, S., Chou, M.-D., Ferrier, B., Johnson, D., Khain, A., Lang, S., Lynn, B. C. Shie, L., Starr, D., Sui, C.-H., Wang, Y., and Wetzel, P.: Microphysics, radiation and surface processes in the Goddard Cumulus Ensemble (GCE) model, Meteorol. Atmos. Phys., 82, 97-137, 2003.

Twomey, S.: The influence of pollution on the shortwave albedo of clouds, J. Atmos. Sci., 34, 1149-1152, 1977.

Twomey, S. and Bohren, C. F.: Simple approximations for calculations of absorption in clouds, J. Atmos. Sci., 37, 2086-2094, 1980 .

Williams, E., Rosenfeld, D., Madden, M. Gerlach, J., Gears, N., Atkinson, L., Dunnemann, N., Frostrom, G., Antonio, M., Blazon, B., Camargo, R., Franca, H., Gomes, A., Lima, M., Machado, R., Manhaes, S., Nachtigall, L., Piva, H., Quintillano, W., Machado, L., Artaxo, P., Roberts, G., Renno, N., 
Blakeslee, R., Balley, J., Boccippio, D., Betts, A., Wolff, D., Roy, B., Halverson, J., Rickenbach, T., Fuentes, J., and Avelino, E.: Contrasting convective regimes over the Amazon: Implications for cloud electrification, J. Geophys. Res., 107(D20), 8082, doi:10.1029/2001JD000380, 2002.

Yang, P., Liou, K. N., Wyser, K., and Mitchell, D.: Parameterization of the scattering and absorption properties of individual ice crystals, J. Geophys. Res., 105, 4699-4718, 2000.

Yuan, T., Martins, J. V., Li, Z., and Remer, L. A.: Estimating glaciation temperature of deep convective clouds with remote sensing data, Geophys. Res. Lett., 37, L08808, doi:10.1029/2010GL042753, 2010.
Zhang, Z., Platnick, S., Yang, P., Heidinger, A. K., and Comstock, J. M.: Effects of ice particle size vertical inhomogeneity on the passive remote sensing of ice clouds, J. Geophys. Res.-Atmos., 115, D17203, doi:10.1029/2010JD013835, 2010.

Zinner, T. and Mayer, B.: Remote sensing of stratocumulus clouds: Uncertainties and biases due to inhomogeneity, J. Geophys. Res., 111(D14), 209, D14209, doi:10.1029/2005JD006955, 2006.

Zinner, T., Marshak, A., Lang, S., Martins, J. V., and Mayer, B.: Remote sensing of cloud sides of deep convection: towards a three-dimensional retrieval of cloud particle size profiles, Atmos. Chem. Phys., 8, 4741-4757, doi:10.5194/acp-8-4741-2008, 2008. 